\title{
The effect of nitric acid surface treatment on CaP deposition of Ti6Al4V open-cell foams in SBF solution
}

\author{
U. Turkan ${ }^{\text {a }}$, M. Guden ${ }^{\text {a,b,c,* }}$ \\ a Department of Mechanical Engineering, Turkey \\ ${ }^{\mathrm{b}}$ Center for Materials Research, Turkey \\ c Dynamic Testing and Modeling Laboratory, Izmir Institute of Technology, Gulbahce Köyu, Urla, Izmir 35430, Turkey
}

\section{A R T I C L E I N F O}

\section{Article history:}

Received 7 May 2010

Accepted in revised form 17 August 2010

Available online 22 August 2010

\section{Keywords:}

Ti6Al4V foam

CaP deposition

Nitric acid

Surface treatment

\begin{abstract}
A B S T R A C T
The effect of nitric acid surface treatment on CaP deposition of an open-cell Ti6Al4V foam (60\% porous and $300-500 \mathrm{~m}$ in pore size), prepared by means of the space holder method using 94 and $66 \mu \mathrm{m}$ average particle size powders, was investigated in a simulated body fluid (SBF) solution up to 14 days. Although, nitric acid surface treatment did not change the foam flat surface roughness values significantly, it increased surface area difference greatly by introducing nano scale undulations on the surface. The increased surface area difference was found to be more pronounced in smaller particle size foam samples. A continuous relatively thin $\mathrm{CaP}$ coating layer formed after 5 and 14 days of SBF immersion in nitric acid surface treated small and larger average particle size foam specimens, respectively. Whereas, the cells of untreated foam specimen were observed to be filled with $\mathrm{CaP}$ precipitates and a continuous $\mathrm{CaP}$ layer development was found after 14 days of SBF immersion. These results were also confirmed with the grazing incidence XRD and FTIR analysis of SBF immersed specimens.
\end{abstract}

(c) 2010 Elsevier B.V. All rights reserved.

\section{Introduction}

The use of porous Ti and Ti6Al4V alloy implants allows a higher degree of bone in-growth and body fluid transport through threedimensional interconnected arrays of pores, improving the interactions with bone and the implant fixation [1]. In addition, the extent of well-known stress shielding, which causes implant loosening, can be further reduced with the use of a low elastic modulus porous implant structure [2]. Certain implant applications of Ti alloy foams have also been exploited as the spinal inter body fusion cages used in spinal surgery for bone fixation [3,4]. Calcium phosphate (CaP) coating of porous surfaces including Ti mesh $[5,6]$ and the sintered bead surface coatings $[7,8]$ were previously investigated. In addition, various surface treatments were applied in conjunction with the biomimetic CaP coating to fulfill the requirement for in vivo bone growth namely the formation of $\mathrm{CaP}$ (bone like apatite). Bone like apatite coating on Ti improves the surface osteoblast cell adhesion and differentiation [9] and increases the bone bonding strength by allowing an early bone apposition to the implant [10].

In a previous study, it was reported that alkali treatment was a perquisite for a uniform biomimetic CaP coating layer deposition on the inner pores of a $40 \%$ porous and $100-300 \mu \mathrm{m}$ pore size sintered $\mathrm{Ti}$ powder compact [11]. The size of porous network structure (sodium

\footnotetext{
* Corresponding author. Izmir Institute of Technology, Gulbahce Koyu, Urla, Izmir 35430, Turkey. Tel.: +90232 7506779; fax. + 902327506701 .

E-mail address: mustafaguden@iyte.edu.tr (M. Guden).
}

titanate hydrogel) formed as a result of alkali treatment increased with increasing molar concentration of $\mathrm{NaOH}$, while $\mathrm{Ti}$ compact samples (40\% porous and $250 \mu \mathrm{m}$ pore size) with smaller pores of network structure showed no apatite deposition after 28 days of SBF immersion [12]. The lack of apatite formation on the compact particle surfaces with smaller pore sizes of the network structure was attributed to low solute concentrations reaching inside the pores. A critical molar concentration of $\mathrm{NaOH}$, after which a smooth surface layer formed and resulted in no apatite nucleation after 3 days of SBF immersion was also reported [13]. The effect of subsequent heat treatment was found to increase the adherence of sodium titanate layer to the Ti substrate [13] and induce a finer porous reticulate structure [14]. The previous investigations outlined above were mainly concentrated on the biomimetic CaP coating of alkali treated sintered powder compacts. It is known that Ti and Ti6Al4V implants are subjected to a passivation treatment to minimize corrosion. ASTM-F86 standard used for surface passivation refers to an acid solution of $20-40 \%$ nitric acid. It was previously shown that nitric acid treatment of a grade $4 \mathrm{Ti}$ ( $65 \%$ solution at $60{ }^{\circ} \mathrm{C}$ for $600 \mathrm{~min}$ ) increased the surface energy nearly $24 \%$ as compared with polished Ti [15]. The surface energy change was also shown to decrease with decreasing acid concentration, temperature and the duration of the treatment [16]. Despite many studies performed on the surface properties of nitric acid treated bulk $\mathrm{Ti}$, there has been no experimental investigation on the effect of nitric acid treatment on the surface properties of porous Ti structures. The present study was therefore conducted in order to investigate the effect of nitric acid treatment on 
the biomimetic CaP deposition in an open-cell Ti6Al4V foam, potentially being used in hard tissue applications. Nitric acid treatment, which is a standard method for the passivation of the implants, may also be considered as an alternative method to the alkali surface treatment.

\section{Materials and methods}

\subsection{Foam preparation and surface treatment}

Open-cell Ti6Al4V foams with $\sim 60 \%$ porosity were prepared by means of the space holder method [17]. Two different particle sizes of gas atomized spherical Ti6Al4V powders (Crucible Research) were used to make foams. The chemical compositions of powders were the same and complied with ASTM 1580-1 standard [18]. Powder 1 (P1) was $45-150 \mu \mathrm{m}$ in particle size, with an average particle size of $94 \mu \mathrm{m}$ and Powder 2 (P2) 30-90 $\mu \mathrm{m}$ in particle size, with an average particle size of $66 \mu \mathrm{m}$. P1 particles were found to show a mono modal particle size distribution, while P2 particles a bimodal particle size distribution. Angular shape ammonium bicarbonate powder (Aldrich) with a particle size range of $315-500 \mu \mathrm{m}$ was used as a space holder. The details of the Ti6Al4V foam preparation, the microstructure development after sintering and mechanical properties are given elsewhere [3]. Briefly, the green powder compacts, compacted uniaxially at $200 \mathrm{MPa}$, were heat treated under a high purity (99.998\%) Ar flux at $200{ }^{\circ} \mathrm{C}$ for $2 \mathrm{~h}$ to remove the space holder and then at $1300{ }^{\circ} \mathrm{C}$ for $1 \mathrm{~h}$ to sinter Ti6Al4V particles. The foams prepared with the above method contained nearly $60 \%$ porosity with a bimodal pore size distribution: macro pores (300-500 $\mu \mathrm{m})$ and micro pores $(1-30 \mu \mathrm{m})$. Micro pores were located in between the sintered Ti6Al4V particles on the cell walls and at the cell edges, while macro pores resulted from the space holder removal.

Fig. 1(a) shows the picture of a sintered foam plate, which is water jet cut for the extraction of the various designed geometries of spinal inter body fusion cages. For in-vitro investigations, small square crosssection plate-like specimens $\left(10 \times 10 \times 3 \mathrm{~mm}^{3}\right)$ were cut from the sintered Ti6Al4V foam plates using a low speed diamond saw (Fig. 1 (b)). The specimens' square cross-sections were then ground sequentially using $120,240,320,600,800,1200$ and 2400 grit SiC papers. The surfaces of foam specimens are composed of ground flat regions and the cells (pores). The foam specimens were cleaned ultrasonically in acetone, then in ethyl alcohol and finally in deionized water for the duration of $15 \mathrm{~min}$ for each solution. Before in-vitro tests, Ti6Al4V foam specimens were exposed to nitric acid treatment in a $1: 1$ volume ratio solution of $\mathrm{HNO}_{3}(65 \%)$ and $\mathrm{H}_{2} \mathrm{O}$ at $60{ }^{\circ} \mathrm{C}$ for $5 \mathrm{~h}$.
This protocol was previously shown to form biomimetic CaP deposition after 3 days of SBF immersion in a bulk Ti [15]. Following the treatment, the specimens were cleaned ultrasonically in deionized water for $15 \mathrm{~min}$ and then dried in air.

\subsection{Bioactivity and characterization}

The SBF solution for in-vitro tests was prepared according to the protocol given in $[19,20]$ by dissolving the following analytical reagents in $1 \mathrm{~L}$ of deionized water: $6.547 \mathrm{~g}$ of $\mathrm{NaCl}, 2.268 \mathrm{~g}$ of $\mathrm{NaHCO}_{3}, 0.372 \mathrm{~g}$ of $\mathrm{KCl}, 0.124 \mathrm{~g}$ of $\mathrm{Na}_{2} \mathrm{HPO}_{4}, 0.305 \mathrm{~g}$ of $\mathrm{MgCl}_{2} \cdot 6 \mathrm{H}_{2} \mathrm{O}$, $0.368 \mathrm{~g}$ of $\mathrm{CaCl}_{2} \cdot 2 \mathrm{H}_{2} \mathrm{O}, 0.071 \mathrm{~g}$ of $\mathrm{Na}_{2} \mathrm{SO}_{4}$ and $6.057 \mathrm{~g}$ of trishydoxmethylaminomethane. The used SBF protocol $(1.5 \times \mathrm{SBF})$ was previously shown to coat untreated Ti6Al4V alloy strips with a CaP layer in 7 days [21]. Each foam specimen was placed into a polypropylene tube containing $6 \mathrm{~mL} \mathrm{SBF}$ solution $(\mathrm{pH}=7.4)$. The tubes were then kept at $37{ }^{\circ} \mathrm{C}$ for 14 days in an incubator. The SBF solution of the tubes was refreshed every $24 \mathrm{~h}$. The crystal structures of the phases of treated and untreated foam specimens before and after SBF immersion were determined using a Philips Xpert X-ray diffractrometer with a Cu-K $\alpha$ X-ray $(\lambda=1.5404 \AA$ for $8.05 \mathrm{keV})$ in grazing incidence (GIXRD) mode. GIXRD was performed at an incident angle of $\omega=0.5^{\circ}$. The effective depth $(\sin \omega / \mu)$ probed by $\mathrm{Cu}-\mathrm{K} \alpha$ was calculated $174 \mathrm{~nm}$. A Philips XL30-SFEG scanning electron microscope (SEM) with an Energy Dispersive X-ray (EDX) analyzer was used for microscopic analyses. The surface topography, surface roughness (Ra) and surface area difference (SAD) of the foam specimens were determined using a Nanoscope-IV Atomic Force Microscope (AFM). AFM analyses were performed using tapping tips (Vecco otespa) with a spring constant of $20-100 \mathrm{Nm}^{-1}$. The scanned area was selected $1.5 \times 1.5 \mu \mathrm{m}$, with vertical and lateral resolutions of 0.001 and $2 \mathrm{~nm}$, respectively. At least three AFM surface scans were performed on the randomly selected areas of foam specimen ground flat surfaces and were used to calculate average surface roughness values. A Perkin Elmer Attenuated Total Reflectance Fourier Transform Infrared (ATRFTIR) Spectrometer was used to analyze the band structure of the coating layer. The band structure was scanned between 525 and $4000 \mathrm{~cm}^{-1}$.

\section{Results}

The GIXRD spectra of untreated and nitric acid treated (NAT) P1 and P2 foams before SBF immersion are shown together in Fig. 2. The $\beta$ phase peak seen in the GIXRD spectra of sintered foams confirms the microscopically observed transformation of the powder (a)

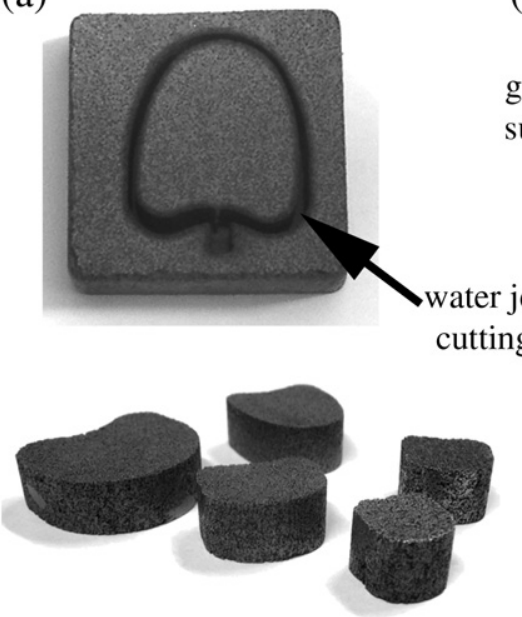

(b)

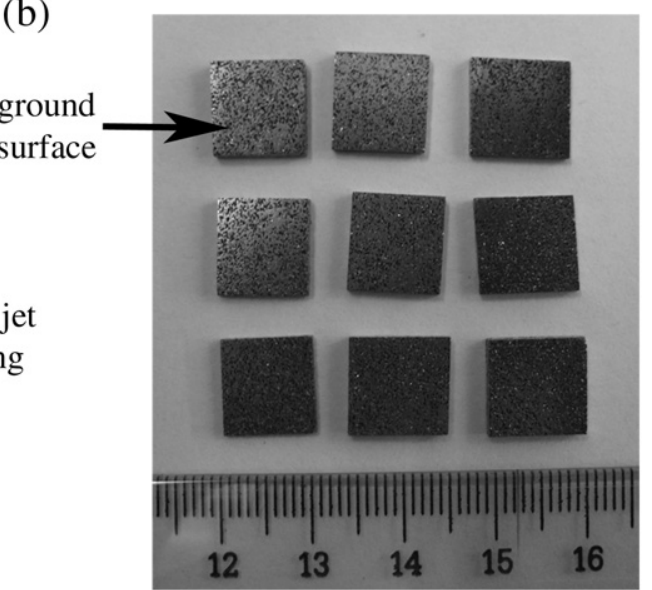



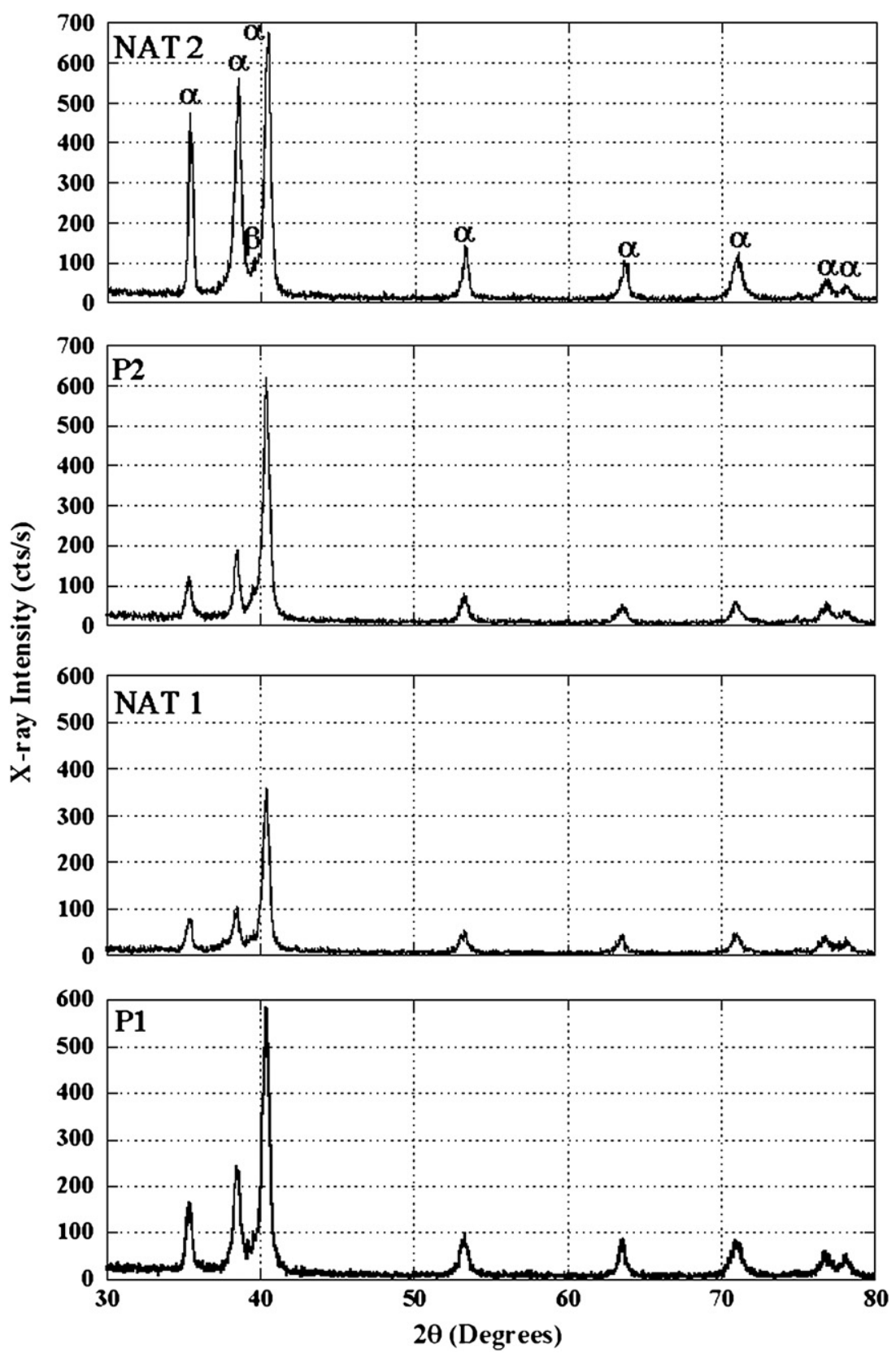

Fig. 2. GIXRD spectra of untreated P1, NAT P1, untreated P2 and NAT P2 foams before SBF immersion.

microstructure from needle-like $\alpha$-phase into Widmanstätten microstructure. The Widmanstätten microstructure comprises the colonies of $\beta$ lathes (bcc and rich in $\mathrm{V}$ ) and $\alpha$ platelets (hcp and rich in $\mathrm{Al}$ ). The SEM pictures of the cells, interior of cell and cell wall flat surfaces (ground) of P1 and P2 foam are shown sequentially in Fig. 3(a-f) and Fig. 4(a-f). Smaller particle sizes of P2 foam as compared with P1 foam are visible in Fig. 3(a) and (b) and Fig. 4(a) and (b). A detailed inspection of the pore sizes (micro pores: remnant of the sintering process) on the cell walls further showed that the cell wall pores of P2 foam were smaller than those of P1 foam. It is also noted in Fig. 3(d) and Fig. 4(d) that the surfaces of NAT particles on the cell walls contain etch lines, resulting from the preferential etching of $\beta$ lathes. The grinding lines are detected on the flat surfaces of untreated P1 and P2 foams (Fig. 3(e)), while nitric acid treatment is noted to partly remove the grinding lines (Fig. 3(f) and Fig. 4(f)). The flat surfaces of NAT foam comprise essentially nano size fine surface undulations, resulting from the acid etching (Fig. 3(f) and Fig. 4(f)).
The foam flat surface AFM micrographs $(1.5 \times 1.5 \mu \mathrm{m})$ of untreated P1 and P2 and NAT P1 and P2 foams before SBF immersion are shown sequentially in Fig. 5(a-d). Since the surface roughness measurements were conducted on a relatively small area, the grinding scratches naturally inducing a macro scale roughness on the surface $(8 \mu \mathrm{m})$ are avoided in the surface roughness measurements. In addition, the AFM measured Ra and SAD values of untreated and NAT P1 and P2 foam flat surfaces are tabulated in Table 1 . The average surface roughness values of NAT foams $(8.778 \mathrm{~nm}$ for P1 and $7.507 \mathrm{~nm}$ for P2 foams) are very much similar to those of untreated foams ( $8.823 \mathrm{~nm}$ for P1 and $7.244 \mathrm{~nm}$ for P2 foams). The surface roughness difference between P1 and P2 foam specimens is most probably related to the difference in average particle size between the starting powders and in the final microstructure of the foams after sintering. It is noted in Table 1 that nitric acid treatment increases the SAD values of the foam flat surfaces. The increase in the SAD value is more pronounced in NAT P2 foam. This also agrees with the AFM surface 

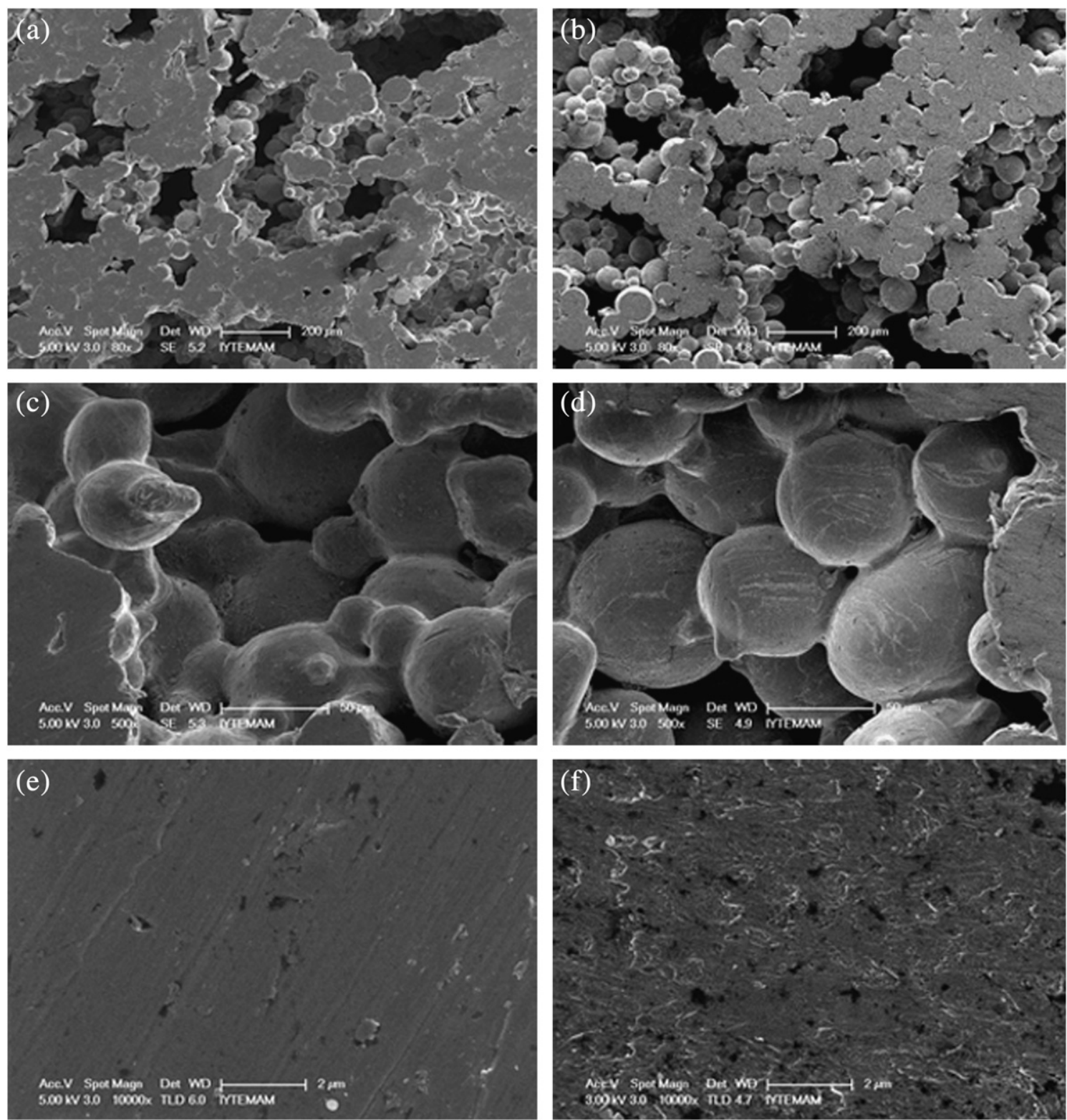

Fig. 3. SEM pictures of P1 foam cellular structure, interior of a cell and foam flat surface before SBF immersion: (a), (c) and (e) untreated foam and (b), (d) and (f) NAT foam.

topography of NAT foam specimens shown in Fig. 5(c) and (d), which are composed of fine undulations.

Fig. 6 shows the GIXRD spectra of untreated P1 and P2 foams after 7 and 14 days of SBF immersion. In the same figure, CaP layer peaks are marked as "**". The GIXRD spectra shown in these figures indicate that the CaP layer on the untreated foams forms only after 14 days of SBF immersion. Although the substrate peak intensity of the P2 foam is seen to be higher than that of the P1 foam in Fig. 6, the peak intensities of CaP layers of the P1 and P2 foams are nearly the same, showing the similar layer thicknesses. The GIXRD spectrum of untreated 14-day SBF immersed P1 foam specimen in Fig. 6 is further fitted with Gaussian Lorentzion distribution $\left(\mathrm{R}^{2}=0.9\right)$. The fitted spectrum reveals a broad peak at $32^{\circ}$, which is the reflections from the (211), (212) and (300) planes of carbonated-hydroxyl apatite (CHA) at $31.037^{\circ}, 32.057^{\circ}$ and $32.998^{\circ}$, respectively. The GIXRD spectra of the untreated foam specimens further show agreements with the SEM pictures of foam flat surfaces and interior of cells of 5, 7 and 14-day SBF immersed P1 and P2 foams shown in Fig. 7(a-i) and Fig. 8(a-i), respectively. A continuous $\mathrm{CaP}$ layer is detected microscopically from the micrographs shown in Fig. 7(a-i) and Fig. 8(a-i) after 14 days of
SBF immersion in untreated P2 and P1 foam specimens. The cells of untreated foam specimens are also noted to be filled with $\mathrm{CaP}$ precipitates after 14 days of SBF immersion as seen in Fig. 7(g) and Fig. 8 (g)

Fig. 9 shows the GIXRD spectra of NAT P1 and P2 foams after 1, 3, 5, 7 and 14 days of SBF immersion. CHA peaks are seen in the GIXRD spectra of the NAT P1 and P2 foams after 7 and 5 days of SBF immersion, respectively. Fig. 10(a-i) further shows the SEM micrographs of NAT P1 foam flat surfaces and interior of cells after 5, 7 and 14 days of SBF immersion. After 5 days, tiny CaP precipitates are seen on the surface of the particles and the flat surface of the foam (Fig. 10(a-c)). After 7 days of SBF immersion, relatively large sizes of CaP globules are seen both on the particle surfaces and on the surfaces of the flat sections of foam (Fig. 10(d-f)). After 14 days of SBF immersion, a uniform CaP coating layer is seen on the flat sections and the particle surfaces of the P1 foam (Fig. 10(a-i)). Fig. 11(a-i) shows the SEM micrographs of the NAT P2 foam flat surfaces and interior of cells after 5, 7 and 14 days of $\mathrm{SBF}$ immersion. The globular CaP precipitates on the flat surface and interior of the cells form in the NAT P2 foam only after 3 days of SBF immersion (not shown here). However, after 5 days of SBF immersion, 

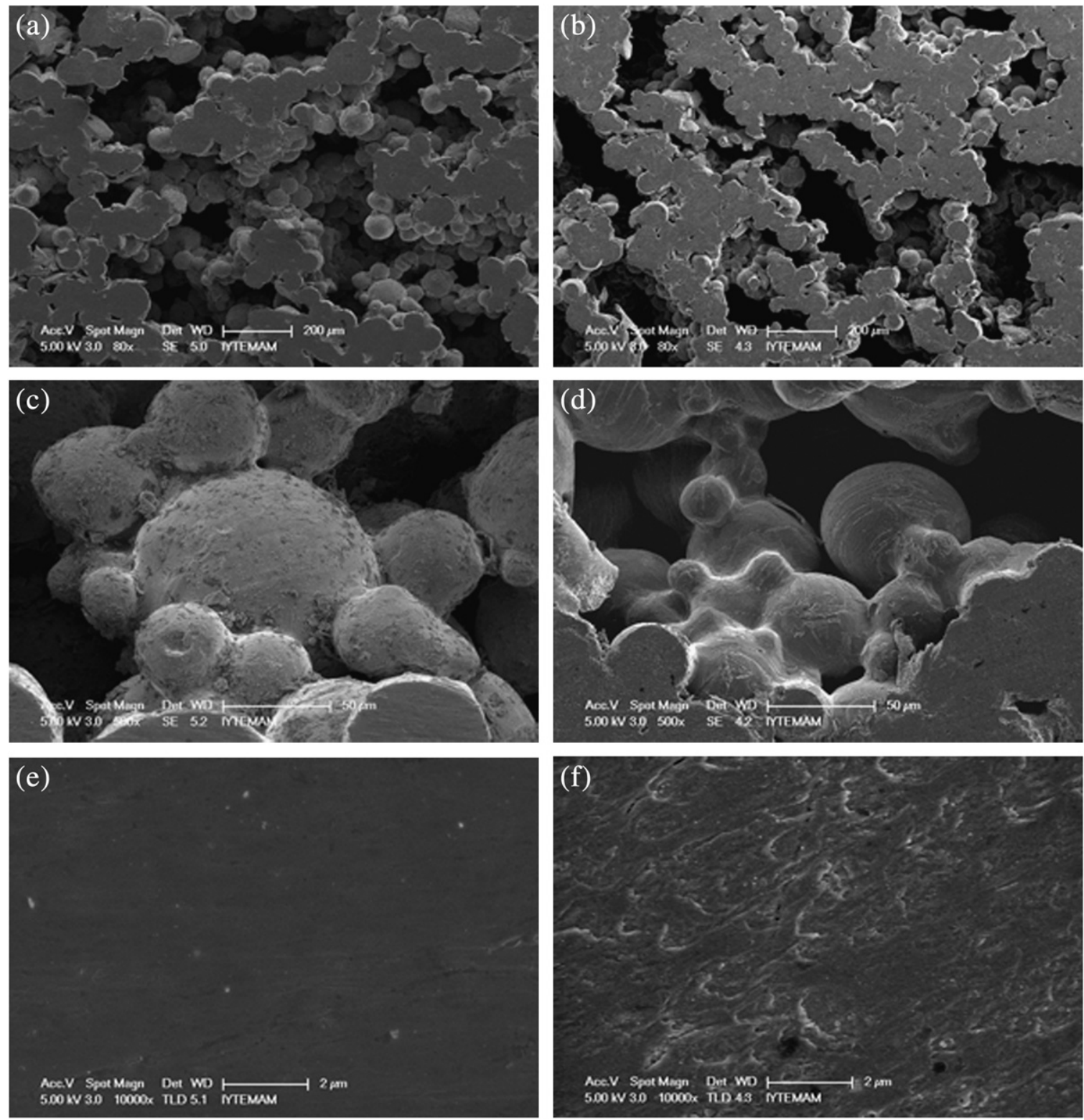

Fig. 4. SEM pictures of P2 foam cellular structure, interior of a cell and foam flat surface before SBF immersion: (a), (c) and (e) untreated foam and (b), (d) and (f) NAT foam.

the flat sections and particle surfaces are fully coated with a uniform CaP layer as shown in Fig. 11(a-c). Fig. 12 shows the ATR-FTIR spectra of untreated and 14-day SBF immersed P2 foam. The absorption band at $3450 \mathrm{~cm}^{-1}$ and bending mode at $1650 \mathrm{~cm}^{-1}$ in Fig. 12 are associated with water. The peaks observed at 1040, 604 and $567 \mathrm{~cm}^{-1}$ are due to the stretching of $\mathrm{PO}_{4}^{3-}$ vibrations and only seen after 14 days of SBF immersion. The phosphate has a tetrahedral structure with four normal modes of vibrations $\left(v_{1}, v_{2}, v_{3}\right.$ and $\left.v_{4}\right)$. Only $v_{3}$ and $v_{4}$ are active on the basis of molecular symmetry. The peaks seen at 959 and $875 \mathrm{~cm}^{-1}$ indicate the presence of $\mathrm{HPO}_{4}^{2-}$ group. The bands detected at 1420 , 1410 and $875 \mathrm{~cm}^{-1}$ show the presence of $\mathrm{CO}_{3}^{2-}$ group. The band at $1550 \mathrm{~cm}^{-1}$ labels the B-CHA type of $\mathrm{CO}_{3}^{2-}$ ion. The carbonate band around $875 \mathrm{~cm}^{-1}$ is due to the bending out of plane vibration, while the band at $1550 \mathrm{~cm}^{-1}$ is the bending mode of the carbonate band [22]. Fig. 13(a) and (b) show the ATR-FTIR analyses of NAT P1 and P2 foams after 1, 3, 5, 7 and 14 days of SBF immersion, respectively. These graphs confirm the CaP formation after 7 days of SBF immersion in the NAT P1 foam specimen (continuous CaP layer microscopically formed after 14 days of immersion) and 5 days of SBF immersion in the NAT P2 foam specimen. No phase shift is observed in the spectra of NAT foam specimens. One of the major problems in the ATR-FTIR analysis of porous samples is the very strong IR absorbance of water (humidity in air). Water vapor has very sharp IR absorption bands around 1700 and $3700 \mathrm{~cm}^{-1}$ that are hard to correct. Therefore, the small IR bands in the spectra that are not marked are due to the water in the pores. This may be prevented by purging the foam specimen with dry nitrogen or by operating the FTIR spectrometer in vacuum.

Fig. 14(a-d) shows sequentially 3D AFM micrographs of the surface topologies of untreated P1 and P2 and NAT P1 and P2 foams after 14 days of SBF immersion. In Fig. 14(b), crack-like valleys are seen on the surface of the untreated $\mathrm{P} 2$ foam. These result from the peeling off $\mathrm{CaP}$ layer on the flat sections of the foam specimen, further agreeing with the SEM pictures of the CaP layer on untreated foam samples (Fig. 7(h)). This further confirms a weak bonding (adhesion) between the CaP film and the particle surface in untreated foam specimens. No CaP layer peeling off is detected on the AFM micrographs of NAT foam specimen surfaces. AFM surface roughness values of foam specimens (untreated and surface treated) after SBF immersion are tabulated in Table 2. As is tabulated in Table 2, the AFM surface roughness values of SBF immersed foam specimens are higher 

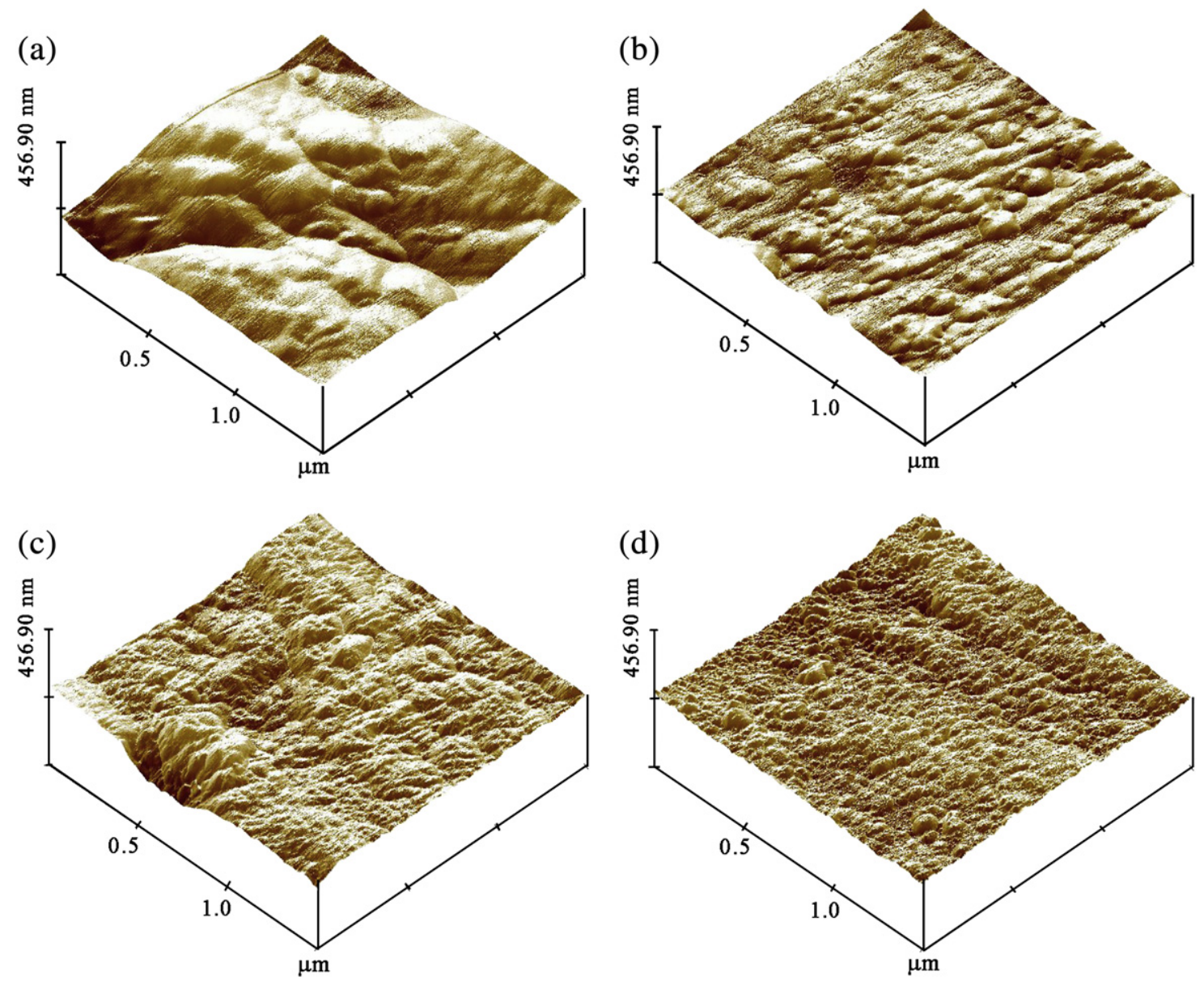

Fig. 5. AFM surface topology of (a) untreated P1, (b) untreated P2, (c) NAT P1 and (d) NAT P2 foam flat surface before SBF immersion.

than those of untreated and treated foam specimens before SBF immersion (Table 1). SBF immersion increases the surface roughness values at least 3.2 times.

\section{Discussion}

The bioactivity of Ti metal depends on the surface characteristics including surface topography, surface roughness, surface energy and the amounts of amphoteric Ti-OH groups. The mechanism of apatite formation on alkali and heat treated $\mathrm{Ti}$ in SBF has been recently demonstrated by Kokubo et al. [23]. Initially, the surface passive $\mathrm{TiO}_{2}$ layer on $\mathrm{Ti}$ is partially dissolved by the corrosive attack of the hydroxyl group, producing negatively charged hydrates, $\mathrm{HTiO}_{3}^{-} \cdot \mathrm{nH}_{2} \mathrm{O}$, which react with positively charged alkali ions in aqueous solution, forming a porous thin sodium titanate gel layer on the surface of $\mathrm{Ti}$ $[13,14,23,24]$. Sodium titanate layer releases $\mathrm{Na}^{+}$ions by exchanging with $\mathrm{H}_{3} \mathrm{O}^{+}$ions in the SBF, forming Ti-OH functional groups on the surface. Then, the reaction between the positively charged $\mathrm{Ca}^{2+}$ ions in the SBF and the negatively charged $\mathrm{Ti}-\mathrm{OH}$ functional group on the

Table 1

The AFM surface roughness and specific area difference of untreated and surface treated P1 and P2 foam specimens before SBF immersion.

\begin{tabular}{lll}
\hline & Ra $(\mathrm{nm})$ & SAD $(\%)$ \\
\hline Untreated P1 & 8.823 & 1.279 \\
NAT P1 & 8.778 & 3.832 \\
Untreated P2 & 7.244 & 1.284 \\
NAT P2 & 7.507 & 7.815 \\
\hline
\end{tabular}

Ti surface results in the formation of a calcium titanate layer. Later, this layer is replaced by an amorphous calcium phosphate layer through the reaction between the positively charged Ti surface and the negatively charged phosphate ions in SBF. The calcium phosphate layer finally transforms into a stable crystalline bonelike apatite.

Acid etching $\left(\mathrm{HCl}+\mathrm{H}_{2} \mathrm{SO}_{4}\right)$ was previously shown to dissolve the natural oxide layer and formed a relatively rough surface on $\mathrm{Ti}$ [25]. On

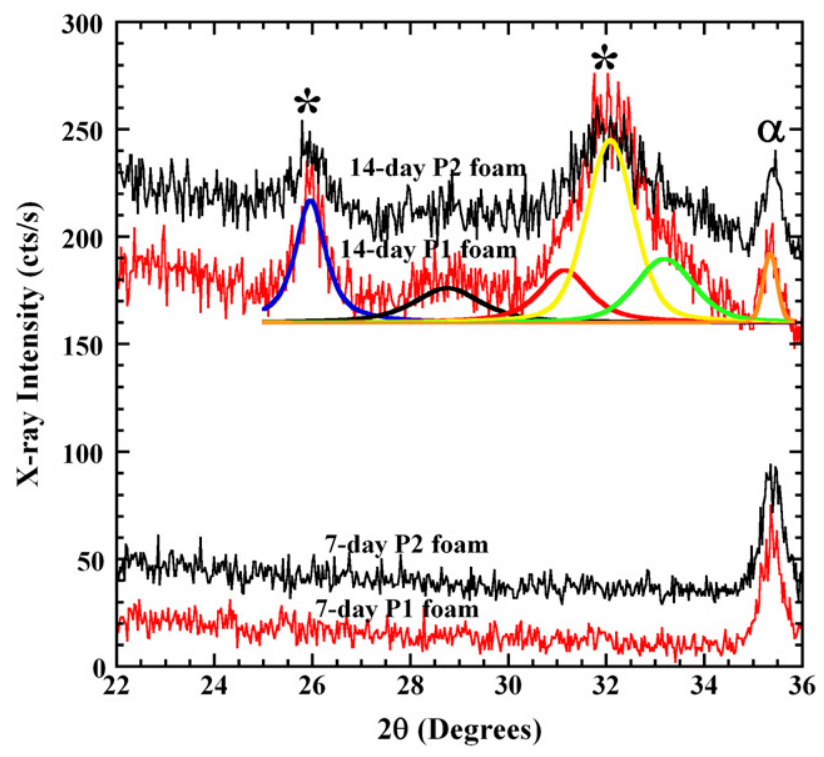

Fig. 6. GIXRD spectra of untreated P1 and P2 foams; after 7 and 14 days of SBF immersion. 

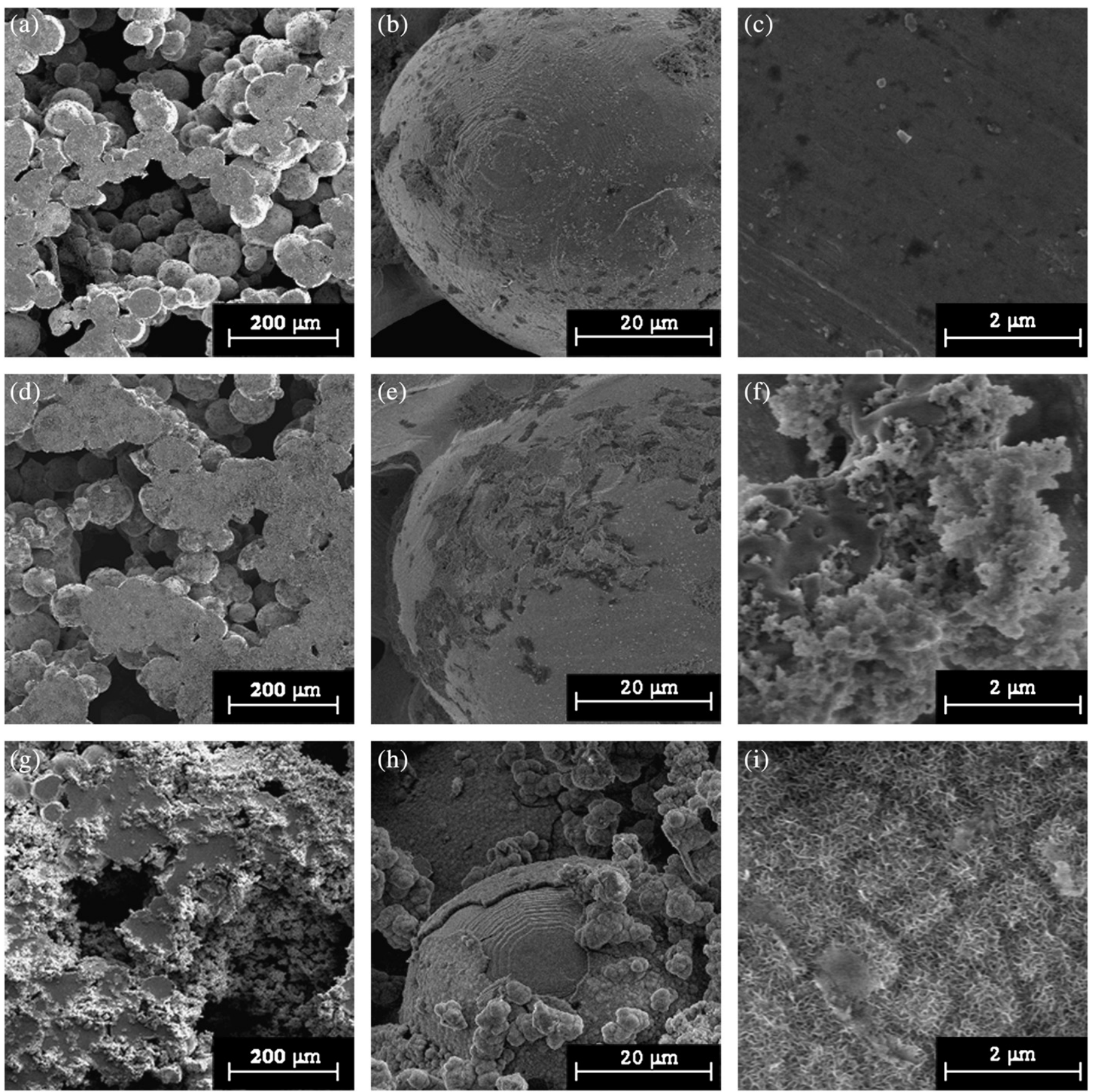

Fig. 7. SEM micrographs of untreated P1 foam flat surface, surface of a particle interior of a cell and magnified view of foam flat surface: (a) (b) and (c) after 5 days of SBF immersion, (d),(e) and (f) after 7 days of SBF immersion and (g), (h) and (i) after 14 days of SBF immersion.

the other hand, nitric acid treatment was shown not to affect the surface roughness, but decreased the thickness of the naturally formed oxide layer on the surface [26,27] and increased the surface energy [15]. In the present study, the AFM surface roughness values of NAT foams are nearly the same with those of untreated foams, agreeing with the results of Lu et al. [15] and Sittig et al. [28]. This also confirms relatively low dissolution rates of $\alpha$ and $\beta$ phases in nitric acid. Barrere et al. [29] showed that the surface topography of Ti6Al4V had no effect on the heterogeneous nucleation of CaP, while the growth and mechanical attachment of CaP coating strongly depended on the surface roughness; a rougher surface $\left(R_{\max }>0.1 \mu \mathrm{m}\right)$ was much more effective for the CaP mechanical attachment to the surface. The variations of Ra and SAD values of NAT P1 and P2 foams with SBF immersion time are shown in Fig. 15. The surface roughness decreases in the first three days of SBF immersion in both foams. Then, the surface roughness increases rapidly to $22 \mathrm{~nm}$ in P1 and $49 \mathrm{~nm}$ in P2 foam after 7 days of SBF immersion. After 14 days of SBF immersion, the surface roughness increases to $28 \mathrm{~nm}$ in P1 and $64 \mathrm{~nm}$ in P2 foams. Similarly, SAD increases with increasing immersion time, while the increase in P2 foam is much higher. In the first 3 days of SBF immersion, the decrease in the surface roughness values may be attributed to the formation of an amorphous CaP layer on the surface or a slow etching action of the SBF solution of the surface. While, the GIXRD and SEM analysis are not able to analyze this very thin amorphous layer formed on the surface. 

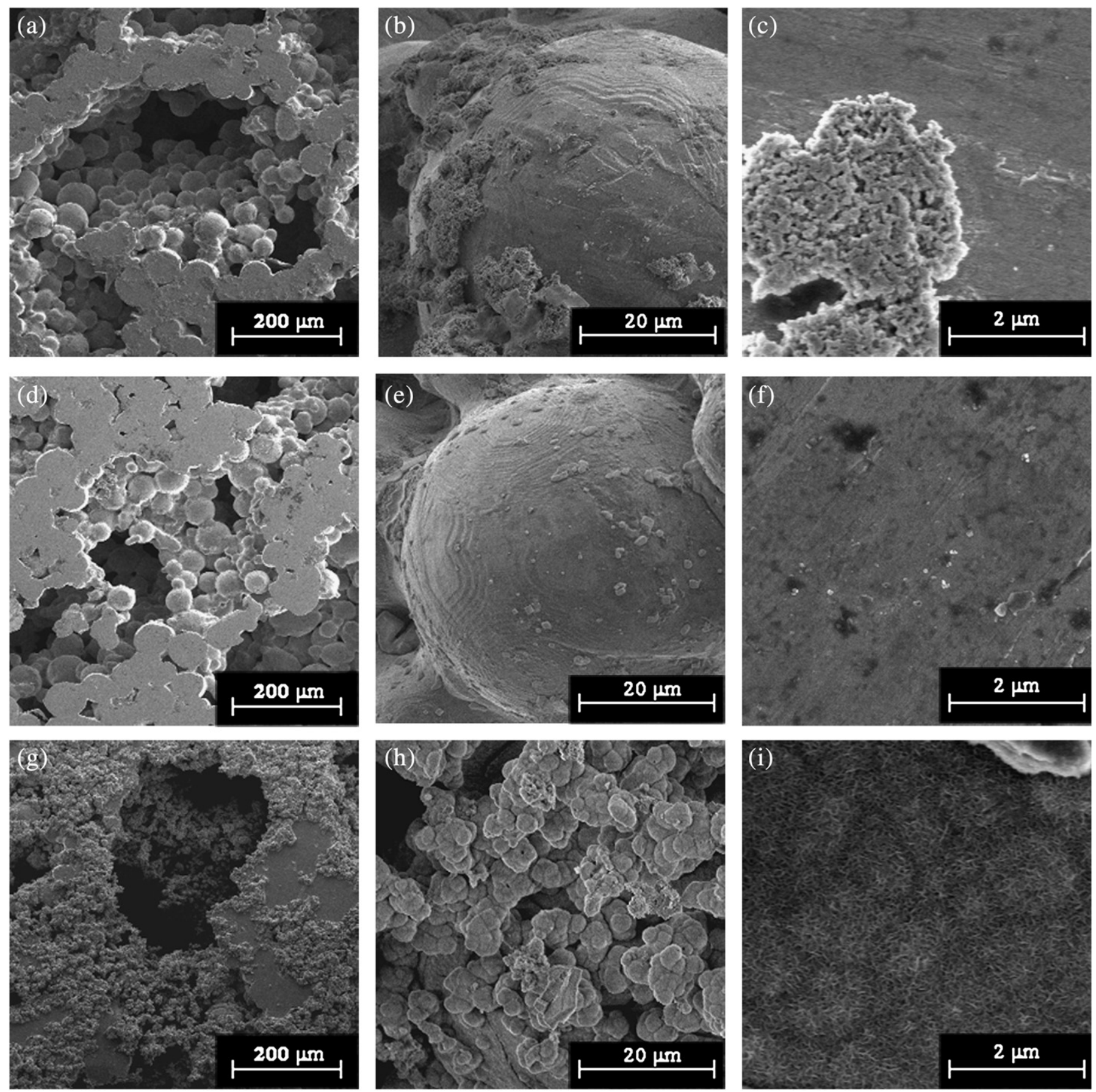

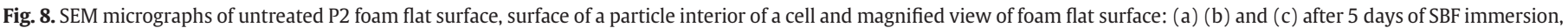
(d),(e) and (f) after 7 days of SBF immersion and (g), (h) and (i) after 14 days of SBF immersion.

Nitric acid treatment decreases the time for the formation of a continuous CaP layer on the foam flat surface and interior parts of the pores from 14 days in untreated foams to 5 and 14 days of SBF immersion. The biomimetic CaP coating ability of nitric acid treatment was attributed to the increased surface energy, leading to lower energy barrier for heterogeneous nucleation [15]. The specific particle surface area of $\mathrm{P} 2\left(0.112 \mathrm{~m}^{2} / \mathrm{g}\right)$ is about twice that of P1 $\left(0.0694 \mathrm{~m}^{2} / \mathrm{g}\right)$. A higher value of SAD combined with a higher specific particle surface area in NAT P2 foam is likely to lead to a higher adsorption rate to the surface and an earlier CaP layer formation on the particles. Lastly, the bonding strength of the CaP layer to NAT P1 and P2 foam particles and the mechanism of early deposition of the $\mathrm{CaP}$ layer on NAT foam particles will be investigated in a further study.

\section{Conclusions}

The effects of nitric acid surface treatment on the CaP deposition of an open-cell Ti6Al4V foam ( $60 \%$ porous and $300-500 \mu \mathrm{m}$ in pore size) developed for biomedical applications and prepared by means of the space holder method using 94 and $66 \mu \mathrm{m}$ average particle size powders were investigated in an SBF solution up to 14 days. Small square cross-section plate-like specimens $\left(1 \times 10 \times 3 \mathrm{~mm}^{3}\right)$ were used in in-vitro investigations and the specimens' square cross-sections were ground sequentially up to 2400 grit SiC paper. The surface roughness values of the ground flat surfaces of the surface untreated and treated specimens were measured before and after SBF immersion in nano metric scale using an AFM. Although nitric acid 


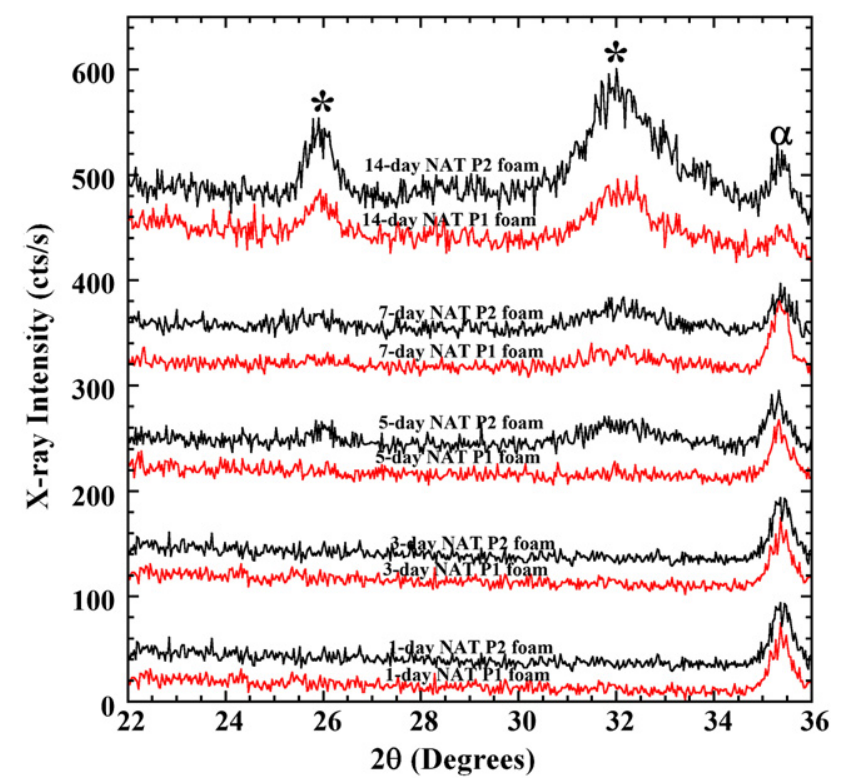

Fig. 9. GIXRD spectra of NAT P1 and P2 foams after 1, 3, 5, 7 and 14 days of SBF immersion.

surface treatment did not change the foam flat surface roughness values significantly, it tended to remove the grinding lines and increased surface area difference greatly by introducing nano scale undulations on the surface. The increased surface area difference was found to be more pronounced in smaller particle size foam samples. A continuous relatively thin $\mathrm{CaP}$ coating layer formed after 5 and 14 days of SBF immersion in the nitric acid surface treated small and larger average particle size foam specimens, respectively. Whereas, the cells of untreated foam specimen were observed to be filled with $\mathrm{CaP}$ precipitates and a continuous $\mathrm{CaP}$ layer development in these samples were found after 14 day of SBF immersion. These results were also confirmed with the grazing incidence XRD and FTIR analyses of SBF immersed specimens.

\section{References}

[1] R.M. Pilliar, Journal of Biomedical Materials Research-Applied Biomaterials 21 (1987) 1-33.

[2] M. Long, H.J. Rack, Biomaterials 19 (1998) 1621-1639.
[3] M.E. Dizlek, M. Guden, U. Turkan, A. Tasdemirci, J. Mater. Sci. 44 (2009) 1512-1519.

[4] M. Takemoto, S. Fujibayashi, M. Neo, K. So, N. Akiyama, T. Matsushita, T. Kokubo, T. Nakamura, J. Neurosurg. Spine 7 (2007) 435-443.

[5] T. Tsukeoka, M. Suzuki, C. Ohtsuki, Y. Tsuneizumi, J. Miyagi, A. Sugino, T. Inoue, R Michihiro, H. Moriya, J. Biomed. Mater. Res. B Appl. Biomater. 75B (2005) 168-176.

[6] J.W.M. Vehof, P.H.M. Spauwen, J.A. Jansen, Biomaterials 21 (2000) 2003-2009.

[7] H.Q. Nguyen, D.A. Deporter, R.M. Pilliar, N. Valiquette, R. Yakubovich, Biomaterials 25 (2004) 865-876.

[8] A. Tache, L. Gan, D. Deporter, R.M. Pillar, Int. J. Oral Maxillofac. Implants 19 (2004) 19-29.

[9] F.J. Gil, A. Padros, J.M. Manero, C. Aparicio, M. Nilsson, J.A. Planell, Materials Science \& Engineering C-Biomimetic and Supramolecular Systems 22 (2002) 53-60.

[10] W.Q. Yan, T. Nakamura, K. Kawanabe, S. Nishigochi, M. Oka, T. Kokubo, Biomaterials 18 (1997) 1185-1190.

[11] Q.Y. Zhang, Y. Leng, R.L. Xin, Biomaterials 26 (2005) 2857-2865.

[12] F.H. Liang, L. Zhou, K.G. Wang, Surf. Coat. Technol. 165 (2003) 133-139.

[13] M. Wei, H.M. Kim, T. Kokubo, J.H. Evans, Materials Science \& Engineering CBiomimetic and Supramolecular Systems 20 (2002) 125-134.

[14] B.H. Lee, Y.D. Kim, J.H. Shin, K.H. Lee, J. Biomed. Mater. Res. 61 (2002) 466-473.

[15] X. Lu, Z.F. Zhao, Y. Leng, Materials Science \& Engineering C-Biomimetic and Supramolecular Systems 27 (2007) 700-708.

[16] D.V. Kilpadi, G.N. Raikar, J. Liu, J.E. Lemons, Y. Vohra, J.C. Gregory, J. Biomed. Mater. Res. 40 (1998) 646-659.

[17] C.E. Wen, M. Mabuchi, Y. Yamada, K. Shimojima, Y. Chino, T. Asahina, Scr. Mater. 45 (2001) 1147-1153.

[18] ASTM F 1580-95, Standard specification for titanium and Ti6Al4V alloy powders for coating surgical implants.

[19] D. Bayraktar, A.C. Tas, J. Eur. Ceram. Soc. 19 (1999) 2573-2579.

[20] A.C. Tas, Biomaterials 21 (2000) 1429-1438.

[21] S. Jalota, S.B. Bhaduri, A.C. Tas, Materials Science \& Engineering C-Biomimetic and Supramolecular Systems 27 (2007) 432-440.

[22] S. Koutsopoulos, J. Biomed. Mater. Res. 62 (2002) 600-612.

[23] T. Kokubo, J. Eur. Ceram. Soc. 29 (2008) 1267-1274.

[24] H.M. Kim, F. Miyaji, T. Kokubo, T. Nakamura, J. Biomed. Mater. Res. 32 (1996) 409-417.

[25] X. Lu, Y.B. Wang, X.D. Yang, Q.Y. Zhang, Z.F. Zhao, L.T. Weng, Y. Leng, J. Biomed. Mater. Res. A 84A (2008) 523-534.

[26] B.W. Callen, B.F. Lowenberg, S. Lugowski, R.N.S. Sodhi, J.E. Davies, J. Biomed. Mater. Res. 29 (1995) 279-290.

[27] T.M. Lee, E. Chang, C.Y. Yang, J. Mater. Sci. Mater. Med. 9 (1998) 439-448

[28] C. Sittig, M. Textor, N.D. Spencer, M. Wieland, P.H. Vallotton, J. Mater. Sci. Mater. Med. 10 (1999) 35-46.

[29] F. Barrere, M.M.E. Snel, C.A. van Blitterswijk, K. de Groot, P. Layrolle, Biomaterials 25 (2004) 2901-2910. 

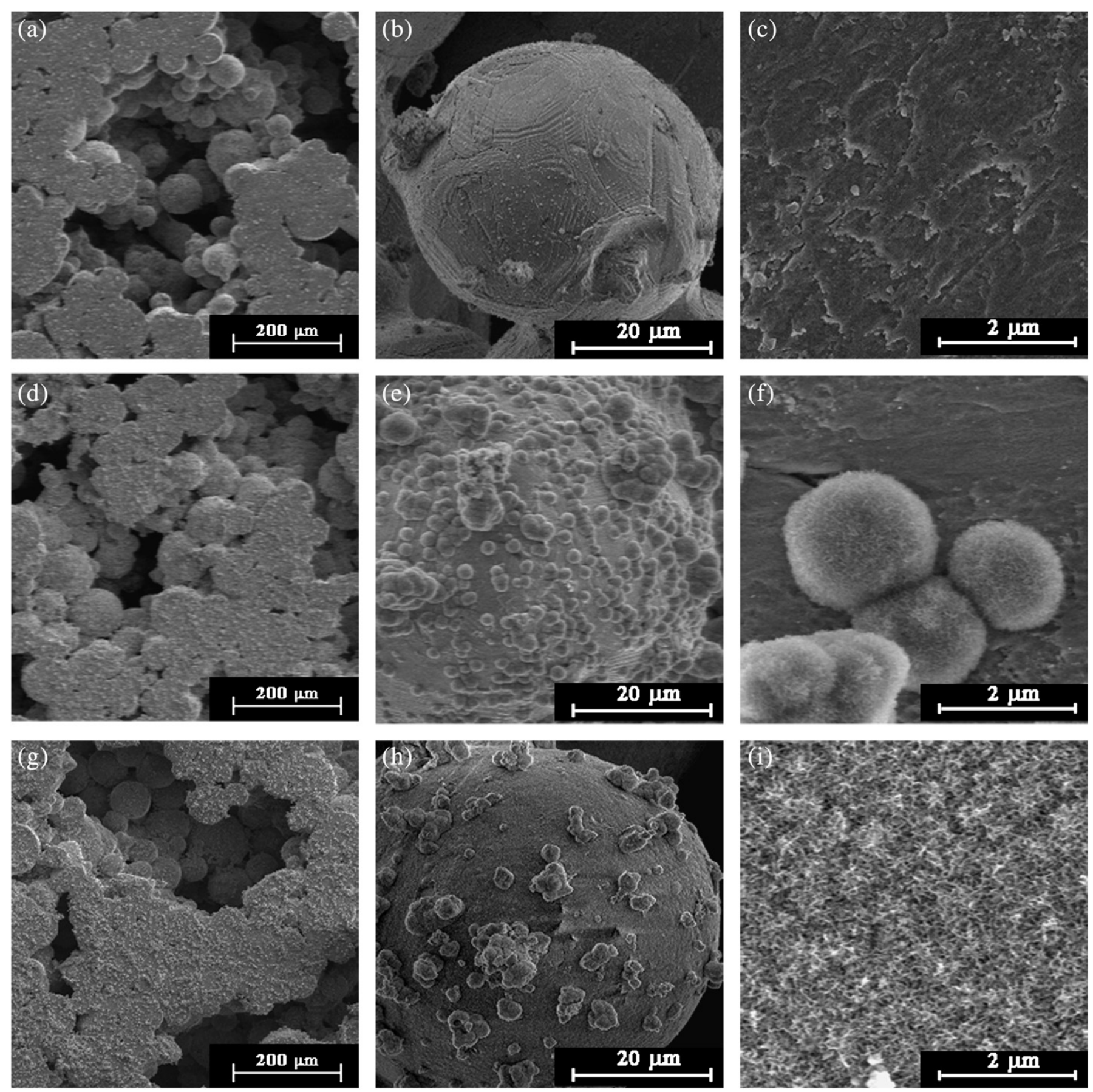

Fig. 10. SEM micrographs of untreated NAT P1 foam flat surface, surface of a particle interior of a cell and magnified view of foam flat surface: (a) (b) and (c) after 5 days of SBF immersion, (d),(e) and (f) after 7 days of SBF immersion and ( $\mathrm{g}$ ), (h) and (i) after 14 days of SBF immersion. 

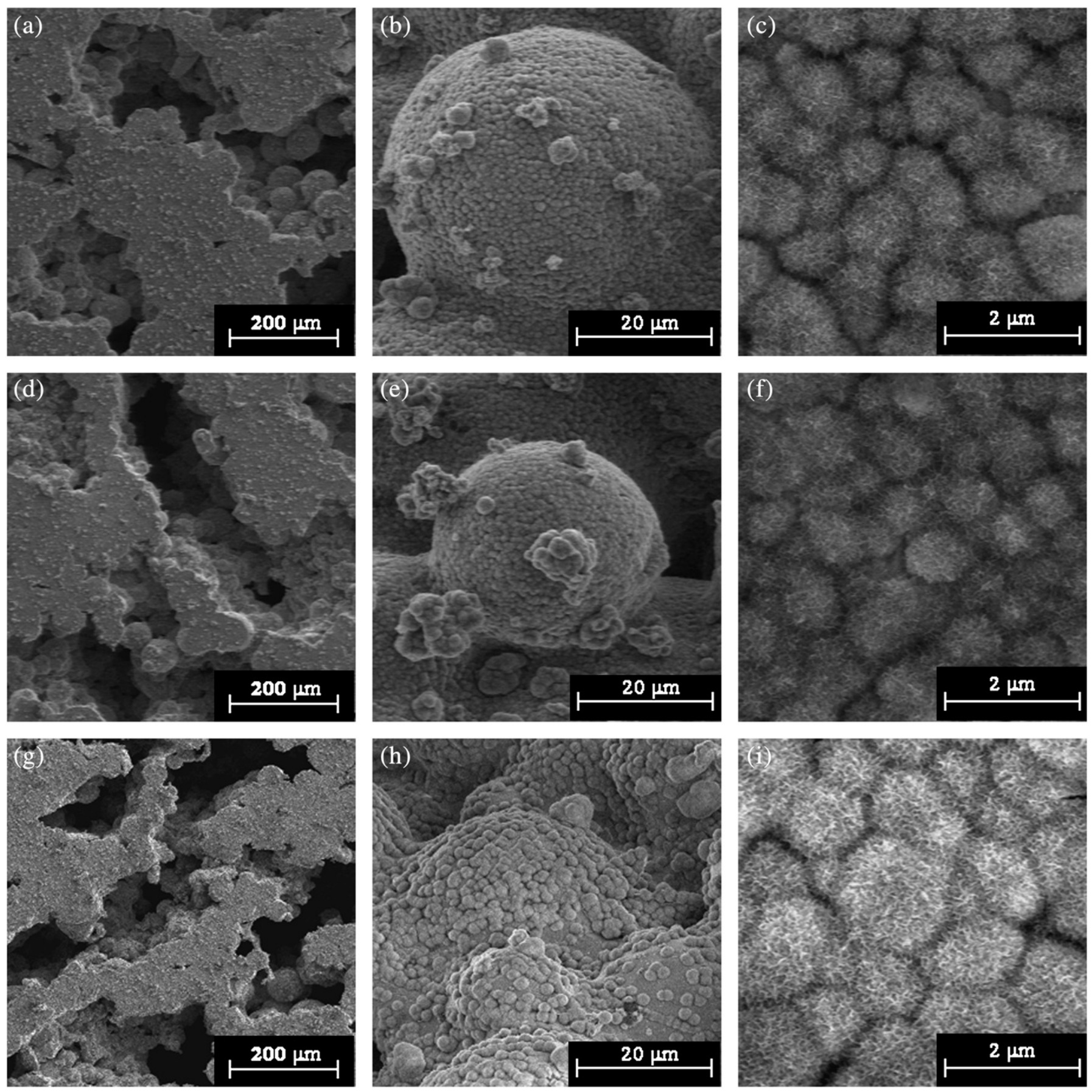

Fig. 11. SEM micrographs of untreated NAT P2 foam flat surface, surface of a particle interior of a cell and magnified view of foam flat surface: (a) (b) and (c) after 5 days of SBF immersion, (d), (e) and (f) after 7 days of SBF immersion and (g), (h) and (i) after 14 days of SBF immersion. 


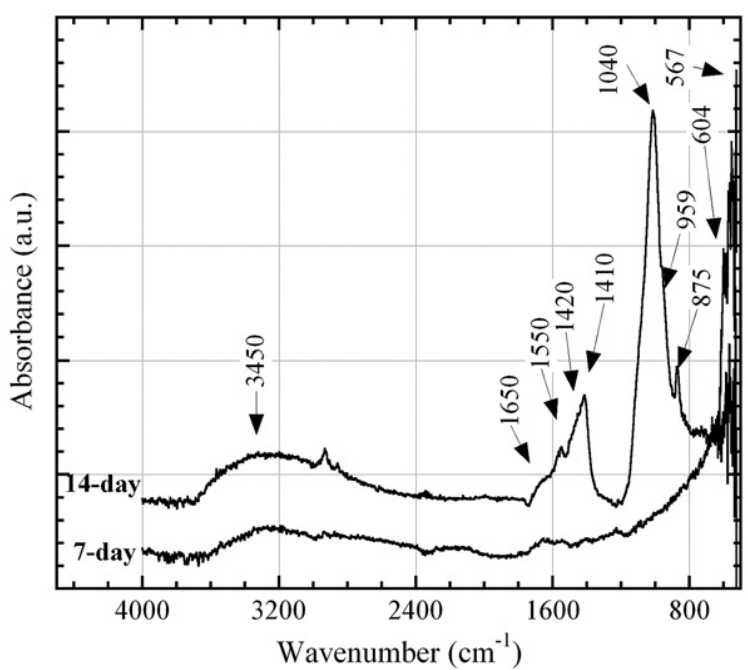

Fig. 12. AT-FTIR spectra of untreated $P 2$ foam after 7 and 14 days of SBF immersion foam.

(a)

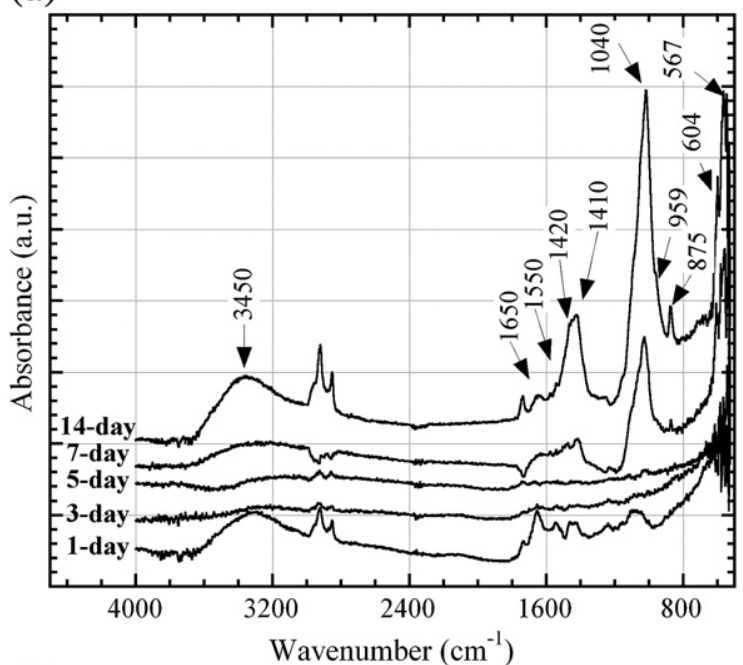

(b)

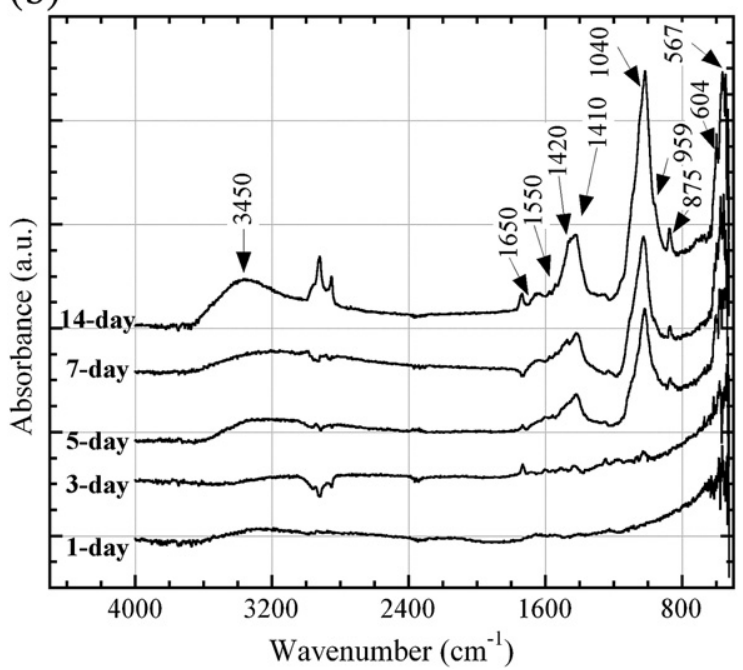

Fig. 13. AT-FTIR spectra of NAT foam after 1, 3, 5, 7 and 14 days of SBF immersion: (a) P1 and (b) P2 foams. 
(a)

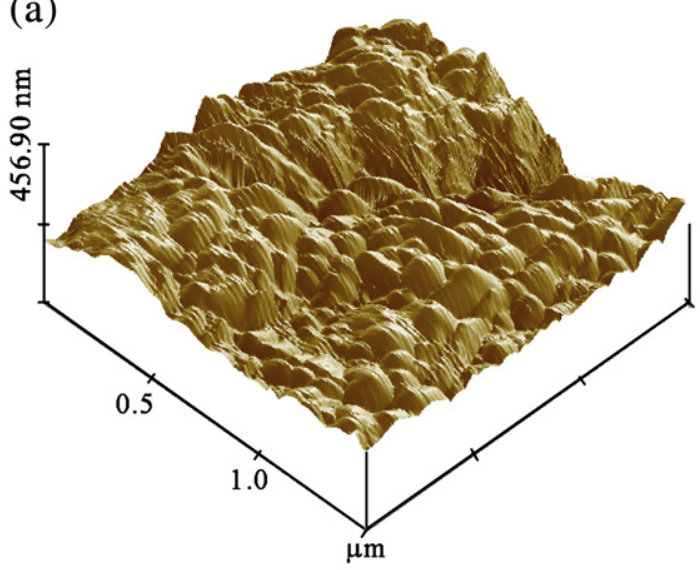

(c)

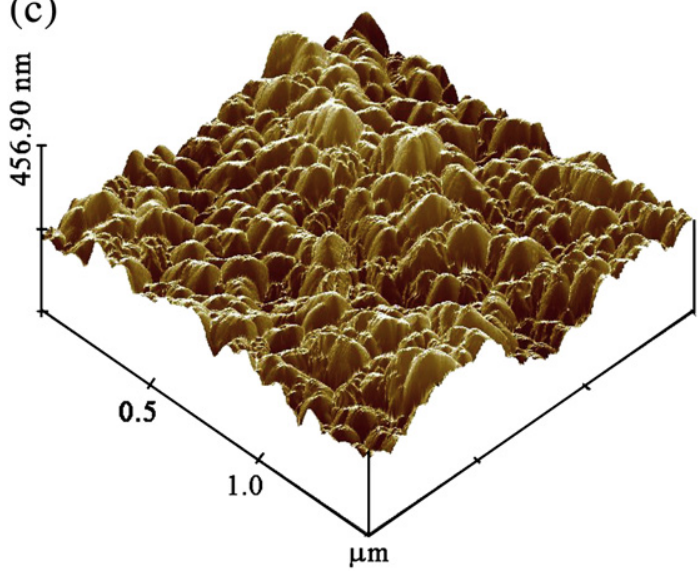

(b)

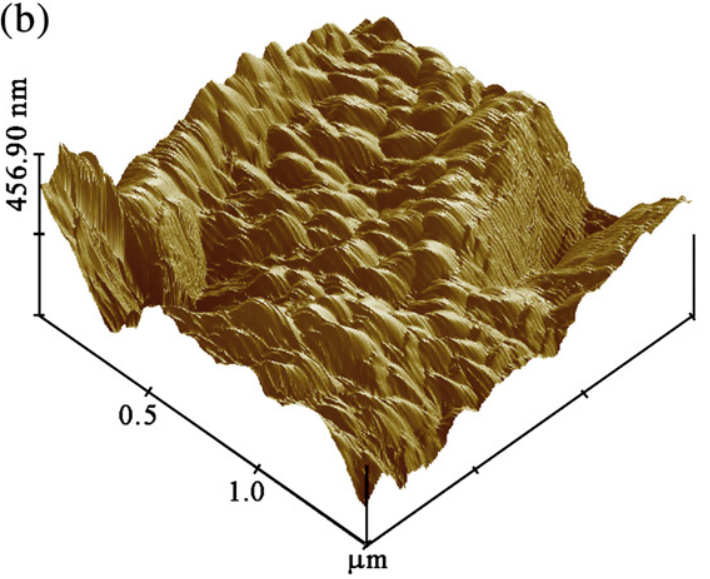

(d)

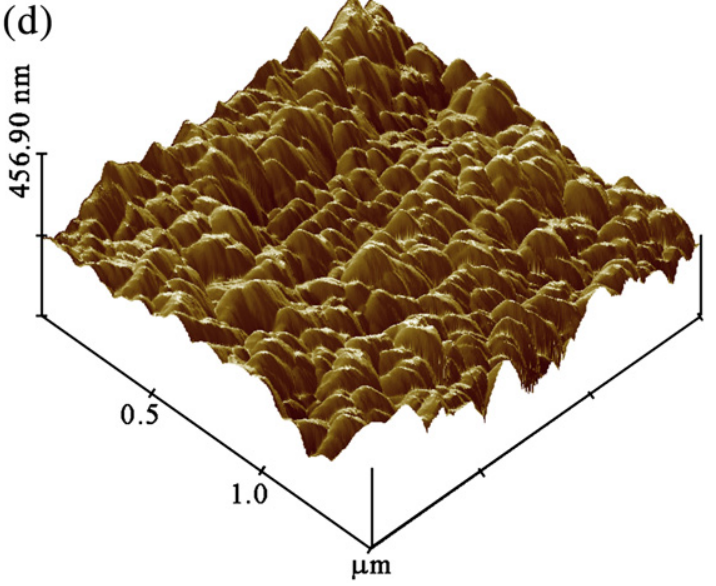

Fig. 14. AFM surface topology of (a) untreated P1, (b) untreated P2, (c) NAT P1 and (d) NAT P2 foam flat surface after 14 days of SBF immersion.

Table 2

The AFM surface roughness of specific area difference of untreated and surface treated P1 and P2 foam specimens after 14 days SBF immersion.

\begin{tabular}{lll}
\hline & Ra $(\mathrm{nm})$ & $\mathrm{SAD}(\%)$ \\
\hline Untreated P1 & 32.035 & 16.659 \\
NAT P1 & 28.394 & 41.581 \\
Untreated P2 & 30.04 & 15.435 \\
NAT P2 & 64.678 & 37.538 \\
\hline
\end{tabular}

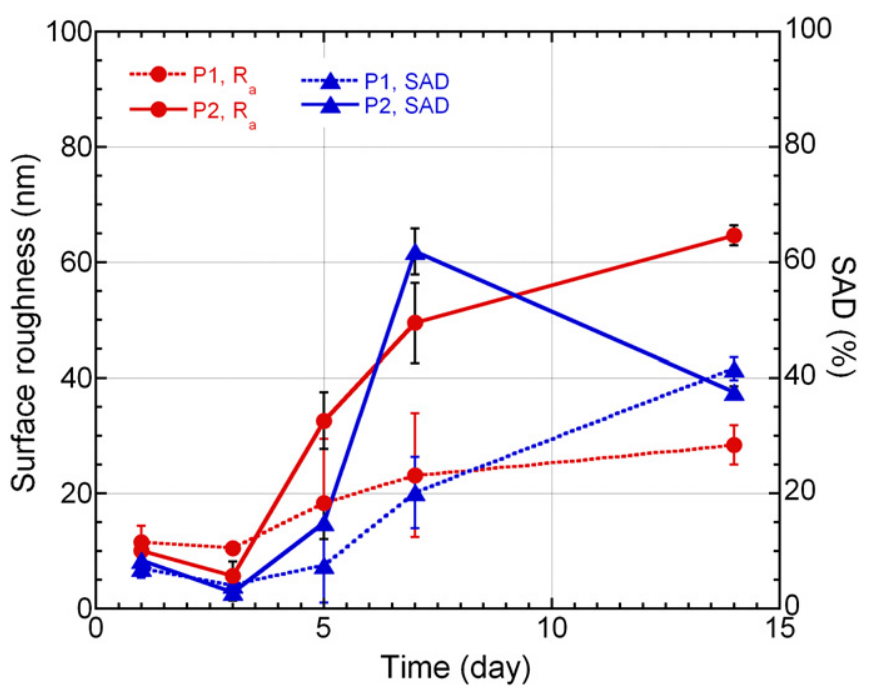

Fig. 15. The variation of the surface roughness and SAD values of NAT P1 and P2 foams with SBF immersion time. 